\title{
A case report of fowl plague keratoconjunctivitis
}

\author{
H. R. TAYLOR \\ From the Department of Ophthalmology, University of Melbourne, Royal Victorian Eye and Ear Hospital, \\ Melbourne, Victoria
}

A. J. TURNER

From the Division of Veterinary Public Health, Department of Agriculture, Melbourne, Victoria

SUMMARY A case of human fowl plague keratoconjunctivitis occurred after accidental laboratory exposure. The conjunctivitis was characterised by follicle formation and a mucopurulent discharge, and ran a self-limiting course over two weeks. The keratitis was of an unusual type and consisted of small intraepithelial opacities, which appeared after one week and resolved completely over the next three weeks. The infection, confirmed by viral culture, was produced by Dutch strain (Hav 1 Neq 1) of fowl plague virus.

Fowl plague is an acute, highly infectious, generally fatal viral infection of fowls. The virus is one of the avian influenza viruses which form part of the orthomyxovirus group. Fowl plague had not been described in Australia when an outbreak occurred on two chicken and one duck properties at Keysborough, Victoria, in January 1976 (Turner, 1976). The isolation of fowl plague virus (FPV) from man has been reported on only one previous occasion (De Lay et al., 1967). This paper reports a confirmed accidental laboratory infection occurring in a human.

\section{Case report}

The patient, a 24-year-old female laboratory technican in good health, splashed allantoic fluids containing FPV on the right side of her face. The accident occurred while opening the tops of infected eggs to harvest allantoic fluids within a biohazard unit, when an egg shattered on handling. At the time the patient believed fluids had come in contact only with the skin, but the face and eye on the right side were washed immediately with water.

Twenty-six hours after the accident the patient noted a foreign body sensation in the right eye, and three hours later a yellow discharge was present, more noticeable under the upper lid. Twelve hours later she reported to her local doctor, who, after taking swabs for culture, prescribed chloramphenicol

Address for reprints: Dr H. R. Taylor, Department of Ophthalmology, University of Melbourne, 32 Gisborne Street, East Melbourne, Victoria 3002, Australia. drops. Over the next 24 hours the right eyelids became more swollen, and the discharge continued until she presented to the casualty section of the Royal Victorian Eye and Ear Hospital. This was 65 hours after exposure and 39 hours after the onset of symptoms.

On examination she had moderate oedema of the right eyelids and enlarged right preauricular lymph nodes. There was a follicular conjunctivitis with 2 to $3 \mathrm{~mm}$ follicles in the tarsal and fornix conjunctiva, and a mucopurulent discharge. The cornea was clear and bright with no epithelial change and normal sensation. The anterior chamber showed no activity. Examination of her left eye was normal. She was otherwise in good health. The chloramphenicol drops were stopped, and 'Zincfrin' drops and saline bathing commenced four times a day.

Twenty-four hours later there was a marked symptomatic improvement and a reduction in the oedema and discharge. Six days later there was a mild residual conjunctival injection and a few small follicles remaining in the fornix. Thirteen small intraepithelial opacities, white-grey in colour, were observed deep in the epithelium (Figs. 1 and 2). These opacities did not involve Bowman's membranes, alter the contour of the overlying epithelium, or stain with Bengal rose or fluorescein. No changes were observed in the anterior chamber. The preauricular nodes were no longer palpable or tender, and the eye felt comfortable. Seven days later, 16 days after exposure, a very faint haze remained in the area of the corneal opacities. The residual conjunctival injection and follicles had cleared. This 


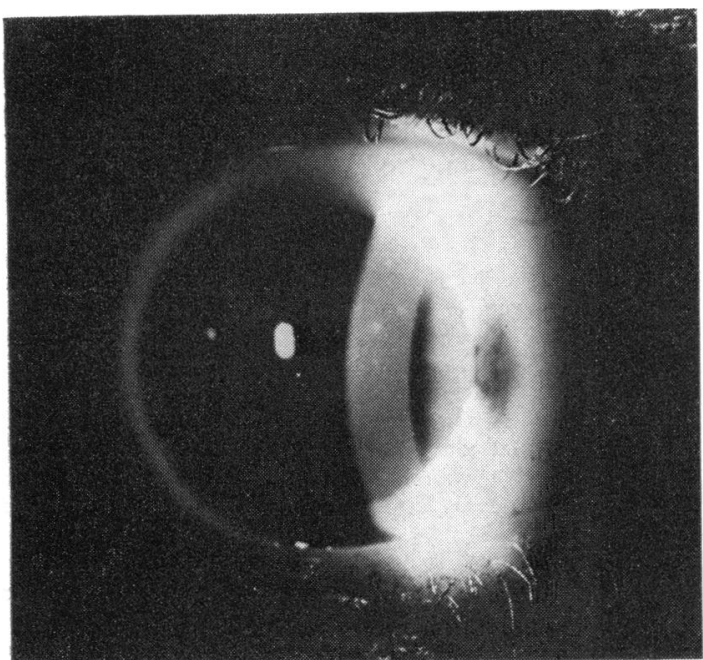

Fig. 1 Clinical photograph taken on day 9 showing several of the intraepithelial corneal opacities

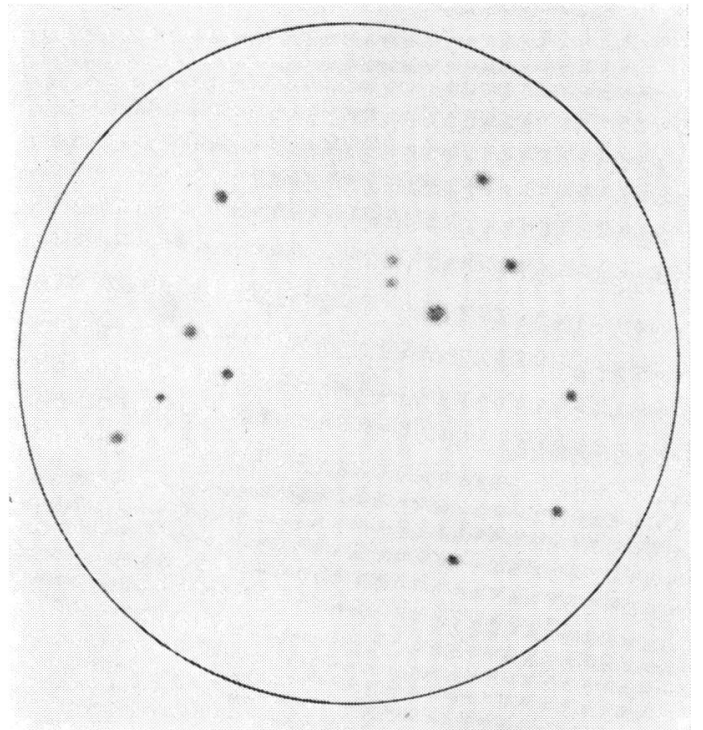

Fig. 2 Drawing showing the distribution of corneal opacities seen on day 9

intraepithelial haze had disappeared in a further seven days, and the ocular examination was entirely normal.

\section{Investigations}

Swabs were collected separately from the medial and lateral canthus and upper and lower lids of the affected eye, and placed into $3 \mathrm{ml}$ brain heart infusion broth, containing 10000 units of penicillin and $10000 \mu \mathrm{g}$ of streptomycin per $\mathrm{ml}$. The samples were returned to the laboratory, and $0.1 \mathrm{ml}$ of sample fluid was inoculated in each of four 10-dayold chicken embryos by the allantoic route. The haemagglutinins in allantoic fluids were identified by the $\beta$-procedure of the haemagglutinationinhibition test using reference fowl plague antiserum and virus (Expert Committee on Respiratory' Virus Diseases).

All eggs inoculated with the four samples were dead at $\mathbf{4 0}$ hours after inoculation, and allantoic fluids contained haemagglutinins for chicken erythrocytes. These haemagglutinins were identified as FPV by the haemagglutination-inhibition test.

Blood samples were taken on 9,16 , and 25 days after exposure. Serum was tested against 4 units of fowl plague haemagglutinin on the haemagglutination-inhibition test (Expert Committee on Respiratory Virus Diseases, 1959). The samples, taken at days 9,16 , and 25 , had titres of 1 in 8,1 in 16 , and 1 in 8 , respectively, when tested for haemagglutination-inhibition antibody.

\section{Discussion}

The patient presented with a typical viral follicular conjunctivitis 26 hours after accidental exposure to FPV. The conjunctivitis had almost run its course when, on the eighth day of the illness, an asymptomatic intraepithelial keratitis was noted. These opacities had cleared within three weeks. The keratitis differed from that seen in other viral infections, such as adenovirus types 3 or 8 or Newcastle disease (Hales, 1973) in that it was asymptomatic, non-staining, and the opacities were situated entirely in the deeper epithelial layers.

FPV was isolated from the conjunctival sac, but a significant four-fold rise in haemagglutinationinhibition titre to FPV was not demonstrated. The first blood sample, however, was not taken until nine days after exposure. The serum titre before or at the time of exposure is unknown, and the titre may have risen before the first sampling. Serum antibody can be detected by day 9 in inoculated chickens, but the titre usually continues to rise until about day 20 . However, acute systemic disease is observed in chickens for a much longer period than eight days.

Human infection with FPV has not been well documented in the past, although FPV can be grown in human cell cultures (Chaproniere and Pereira, 1955). The strain of FPV causing an outbreak of disease in chickens in Victoria in 1976 was Dutch strain, which is antigenically Hav 1 Neq 1 (Turner, 1976). Strains of FPV which have been isolated from 
outbreaks in fowls in other parts of the world have different neuraminidase antigens (Tumova and Schild, 1972). Isolation of Dutch strain of FPV has been previously recorded only from an outbreak in Indonesia in 1927. Human susceptibility to FPV may be dependent on virus strain and individual variability.

The patient reported by De Lay et al. (1967) was suffering from an undiagnosed illness after visiting the Far East and Middle East areas, where fowl plague is enzootic. The virus was cultured from a blood sample. Further study on the isolated virus demonstrated that it was very closely related, if not identical, to FPV (Campbell et al., 1970). However, the incubation time was thought to be 30 days, much longer than that for birds (usually four hours to two days) and no serum antibody was detected.

Fowl plague is characterised in fowls by a viraemia producing oedema, congestion, petechial haemorrhages, and focal areas of necrosis. These changes are seen particularly in the skin, respiratory and enteric tracts, and the nervous system. The ocular involvement consists of a reddened and swollen conjunctiva and periorbital oedema (Stubbs, 1965). It is interesting that this case showed considerable lid oedema, but no petechiae were noted.

\section{References}

Campbell, C. H., Webster, R. G., and Breese, S. S. (1970). Journal of Infectious Diseases, 122, 513.

Chaproniere, D. M., and Pereira, H. G. (1955). British Journal of Experimental Pathology, 36, 607.

De Lay, P. D., Casey, H. C., and Tobiash, H. S. (1967). Public Health Report, Washington, 82, 615.

Expert Committee on Respiratory Virus Diseases (1959). World Health Organisation Technical Report Series, 170.

Hales, R. H., and Ostler, H. B. (1973). British Journal of Ophthalmology, 57, 694.

Stubbs, E. L. (1965). In 'Diseases of Poultry', eds. Biester, H. E., and Schwarte, L. H. 5th ed., p. 813. Iowa State University Press, Ames.

Tumova, B., and Schild, G. C. (1972). Bulletin of World Health Organisation, 47, 453.

Turner, A. J. (1976). Australian Veterinary Journal (in the press). 